\title{
Is Hostility Dancing Along with Conversion and Dissociation?
}

\author{
Balta GT, Angelopoulos NV
}

\begin{abstract}
Background.Hysterical symptoms frequently accompany a variety of neurotic and even psychotic psychiatric syndromes and illnesses.

Methods. The presence and course of these symptoms was investigated in the present study in 73 psychiatric patients. The relationship of conversion symptoms and dissociative symptoms, both two broad dimensions of hysterical symptomatology, with self-reported hostility was examined in particular.

Results.It was found that changes in dissociative symptoms showed highly significant correlations with the changes of externally directed hostility but no significant association with those of internally directed hostility. There was no significant association between changes in hostility and changes in conversion symptoms.

Conclusions.In patients recovering from mental illnesses (acute or relapses), as the dissociative symptoms became less marked so the patients expressed less extrapunitive forms of hostility. Changes in dissociative symptoms correlate significantly with changes in total hostility, as well. Conversion symptoms, on the other hand, do not correlate significantly with changes in these scales. It is also of interest that no significant correlations have been shown between the score changes of the intropunitive subscales with either conversion or dissociative symptoms.
\end{abstract}

Index Terms : Hostility, hysteria, conversion symptoms, dissociative symptoms

\section{INTRODUCTION}

Neurotic symptoms, such as anxiety, depressive, hysterical, or obsessional, are present in the vast majority of psychiatric patients, whether their illness is neurotic or psychotic (Brown 2005, Foulds et al 1976). Work has been done to examine the patterns of association between specific groups of symptoms and case folder diagnosis. Less has been done to see how these symptoms change during the process of the development or recovery of the mental illness.

Hysteria. Before going any further, two important distinctions need to be made. The first is the contrast between hysteria as a cluster of specific personality traits and hysteria as an illness, and the second is between the two broad dimensions of hysteria: conversion hysteria and dissociative hysteria.

Balta GT, M.D, Ph. D, University of Thessaly, Medical School, Department of Psychiatry, Biopolis, Larissa, Greece

Angelopoulos NV, Professor of Psychiatry, University of Thessaly, Medical School, Department of Psychiatry, Biopolis, Larissa, Greece
The term "hysteric personality" denotes a characteristic quality of behavior with character traits such as egocentricity, exhibitionism and histrionic expression, emotionality, dependency, provocativeness, suggestibility and fear of sexuality (Lerner, 1974; Priest and Woolfson, 1986).

Hysteria, on the other hand, as an illness is characterized by the presence of symptoms rather than character traits. The behavior of the patient suggests that the symptoms arise in a situation that is construed by the patient as threatening and result in what is called the 'primary gain' i.e. a lowering of anxiety levels (Priest and Woolfson, 1986). Regardless of the mechanism which triggers the development of hysterical symptoms the patient is rewarded with sympathy when he adopts the sick role, and may be regarded as manipulating others via symptoms and at the same time avoiding those demands of life which are particularly troublesome to him. Hysterical symptoms are not only part of the hysterical neurosis. Empirically they are found as well in patients with other psychiatric syndromes (Foulds, 1965, 1976).

Although hysteria as an illness is more common in hysterical personalities the question of the relationship between these entities is still a matter of discussion. Hysterical traits are not always found in patients with hysterical symptoms (Lasare and Klerman, 1968). Ingham and Robinson (1964) found that, although the mean extraversion score for patients with conversion symptoms was similar to that of patients with anxiety or neurotic depression, the hysterical personalities obtained a more extraverted score. As Caine and Hope (1964) concluded, patients with hysteric symptoms are more extraverted than of patients with anxiety or neurotic depression and more likely to have a hysterical personality.

As far as the terms "conversion hysteria" and "dissociative hysteria" are concerned, the former corresponds to the traditional concept of hysteria. Conversion disorder, refering to the presence of motor and or sensory symptoms for which there are noor inadequate medical explanations (APA 2013), it presents the process by which a mental conflict is transformed into a somatic phenomenon. It has been claimed (Woodruff et al., 1974; Watson and Buramen, 1979) that the blindness, deafness, paralysis and hysterical fits that are described in classical textbooks as the most common conversion symptoms are not in fact currently so common as in earlier years possibly because of everyday psychiatric practice these symptoms have been replaced by other symptoms such as dizziness, headache and other pains, paraesthesia, anaesthesia, pseudoheart attacks and so on. This change in fre- 
quency may be attributed to the increased cultural sophistication of the general public, to a change of the doctors' diagnostic attitudes and other socio-economic and cultural factors. (Akagi et House 2002, Allamet al 2016, Mason 2016, Jensen and Hansen 2016). The common denominator of both the classical and recent conversion symptoms is their apparently somatic character.

Dissociative hysteria, on the other hand, may be regarded as the state in which two or more mental processes coexist without becoming connected or integrated and this results in such symptoms as amnesia or fugue (Humpton et al 2016). Although different in form from conversion symptoms, the underlying psychological mechanisms (e.g. 'primary gain') could be the same. Researchers (Fleming et Resick 2016, Holmes et al 2005, Brown 2006) have proposed diffirentpsychological mechanisms fordifferent types of dissociation andhave looked through the dissociation-PTSD relationship (Armour et al 2014a, Blevins et al 2014, Wolf et al 2012)

Hostility. While symptoms-not only hysterical- change, personality factors (traits and attitudes) are much more enduring. The constellation of attitudes included in the term 'hostility' is widespread among normal population but elevated levels have been observed in the majority of psychiatric illnesses (Foulds, 1965; Foulds and Hope, 1968, Christodoulou et al, 2016 ). The a priori assumption, that hostility, as an attitude, changes more slowly than symptoms has been borne out by empirical observation (Angelopoulos, 1981; Schmidt and Priest, 1981), nevertheless substantial changes in hostility levels do occur with the time span of hospitalization of the average acute psychiatric in-patient (Angelopoulos, 1981).

Not only is it of importance to know the level of hostility and its structure in patients reporting certain psychiatric symptoms, but it also is of interest to know its movement during the course of the symptomatology. The study of the course of both psychiatric symptoms and hostile attitudes during the progress of psychiatric illness could reveal more subtle types of relationship between hostility and psychiatric symptoms. The majority of the studies which examine the relationship between these two factors have been carried out on single occasions. Empirical studies taking into account the course of these phenomena are of limited number and almost entirely confined to the interaction of hostility and depression.

Hysteria and Hostility. Although the relationships between hysterical personality and patterns of hostility have been investigated to some extent, the study of the relationships between hysterical symptoms and patterns of hostility has been rather neglected.

It has been found in various categories of psychiatric patients (Eysenck, 1962; Caine and Hope, 1964) that hysterics were the most extraverted group. Although extraversion does not necessarily imply extraverted hostility, it has been found in practice that there is a positive association between these traits (Foulds, 1965). Rozenzweig (1938) considered conversion hysterics as a group of impunitives (i.e. being neither in- tropunitive nor extrapunitive) and Foulds, (1965, 1976) showed that they produce relatively low scores on intropunitiveness if compared with patients with other neurotic symptoms. He interpreted this as a result of their, at least partial, repression (or dissociation) of painful effect.

It has been suggested (Foulds, 1966) that those who complain predominantly of somatic rather than psychological symptoms should score lower on a questionnaire measure of general hostility and less intropunitively on a measure of direction of hostility, reflecting probably that somatization of symptoms could be a substitute for intropunitiveness. Fernando (1977), however, pointed out that in his study of depressive patients it was not clear that somatic manifestations and guilt feelings were necessarily inversely related in the way Foulds proposed.

On the other hand, dissociative symptoms have a more clearly psychological character than conversion symptoms. It has been suggested (Cameron, 1963; Foulds, 1976) that it is more likely for patients with dissociative symptoms to move towards the expression of delusional states than patients manifesting other neurotic symptoms. It would be expressed therefore that these patients would score higher in general hostility and intropunitiveness than patients with conversion symptoms, since psychotic illnesses are in general associated with high scores on hostility questionnaires.Elbogen and Johnson (2009), after collecting data out of 34.653 subjects, showed that the incidence of violence was higher for people with severe mental illnesses (schizophrenia, bipolar disease).Howard in 2015 (Howard, 2015) suggested that emotion dysregulation/impulsiveness, psychopathy, and delusional ideation conjointly contribute to the increased risk of violence shown by people with Personality Disorders.Evren et al (2013), when studing dissociative and non dissociative male substance-dependent inpatients, found higher aggression scores in the former group than the later. Armour et al, after studied 351 European victims of sexual assault and rape, evidenced significantly higher mean scores on hostility in the dissociative-PTSD group than the nondissociative group (Armour et al, 2014b).

The purpose of the present study was to detect possible associations between the changes of hostility patterns and hysterical symptoms (conversion and dissociative) with the passage of time.

\section{II.METHODS}

The study was a part of a project aiming to investigate the possible relationships between personality factors and twelve distinct psychiatric conditions in hospitalized patients. It was carried out in the Psychiatric Department of St. Mary's Hospital Medical School, London, in a series of consecutively admitted inpatients. Criteria for inclusion were age between 16 and 65 years and the ability to cooperate in the testing procedure. All kinds of psychiatric disturbance were accepted except organic brain disease and mental deficiency. 
The used psychometric instruments were the Hostility and Direction of Hostility Questionnaire (HDHQ), (Caine et al. 1967) and the Conversion symptoms and Dissociative symptoms scales given as part of the Delusions Symptoms States Inventory (DSSI), (Bedford and Foulds, 1978).

The HDHQ is a well known and widely used instrument (Caine et al. 1967; Arrindell et al. 1984; Angelopoulos et al 1995). This is an attitudinal measure of hostility having little implication of actual or aggressive behaviour physically expressed. It reflects a readiness to respond with aggressive behaviour and a tendency to evaluate persons, including the self, in negative and unfavourable terms. It consists of 52 items presented in five subscales. Three subscales, ActingOut Hostility, Criticism of Others, and Paranoid Hostility, are measures of Extrapunitiveness. Two subscales, SelfCriticism and Guilt measure Intropunitiveness. Total hostility is the sum of the five subscales. The Direction of Hostility score indicates a balance between introverted and extraverted hostility and is obtained by the formula: $(\mathrm{AH}+\mathrm{CO}+\mathrm{PH})-$ $(2 \mathrm{SC}+\mathrm{G})$ with positive scores indicating Intropunitiveness and negative scores Extrapunitiveness. Generally, the accepted norms for Total Hostility in normal populations are between 12-14 (Caine et al. 1967) but higher norms have also been suggested (McPherson, 1988).

The DSSI (Foulds and Bedford, 1975; Bedford and Foulds, 1978) is a descriptive rather than a specifically diagnostic instrument. Its items represent salient features of particular clinical conditions. It has no relevance to mental subnormality, to symptomatology resulting from organic brain disease nor to traits of personality disorder. It contains 84 items, divided into twelve subscales of seven items each. These subscales are: state of anxiety, state of depression, state of elation, phobic symptoms, compulsive symptoms, ruminative symptoms, conversion symptoms, dissociative symptoms, delusions of contrition, delusions of grandeur, delusions of persecution, and delusions of disintegration.

The questionnaires were administered during the first week of admission and completed again by the patients after three to six weeks. A minimum acceptable time interval of three weeks was established between the two measurements. The rationale for this time limitation is the hypothesis that a substantial change in psychopathology occurs in no less than a certain period of time.

The statistical analysis was carried out using the Statistical Package for the Social Sciences, SPSS/PC ${ }^{+}$(Norusis, 1992). For the ordinal variables the nonparametric rank order correlation coefficient Kendall's $\tau$-b (Kendall, 1962; Priest, 1976) was used. Briefly, Kendall's $\tau$-b, is a coefficient of association that makes no assumptions about the normality of the underlying distribution of the data (other than that can be seen as categories ranked in order), it is appropriate for the ordinal level of measurement (e.g. rank on one to three on a rating scale) it does not give undue value to outlying scores, gives coefficients of rank ordered correlations and a level of statistical significance and allows a partial correlation coefficient to be calculated if necessary.

\section{RESULTS}

One hundred and thirty two patients completed the first battery of scales and 73 patients $(53.3 \%)$ the second. From the 59 patients who failed to complete the second series, 38 were discharged before the lapse of the minimum acceptable time interval of three weeks and the remaining 21 because either of their psychiatric condition or because they refused, in various ways, to continue their cooperation. Regarding their clinical status on the first measurement, fifty two were in-patients, fourteen day-patients and seven out patients. On the second measurement five of the in-patients became day patients.

The mean age of the participants was 35.2 years (s.d 12.2, min.17, max. 68). The mean time elapsed between the two assessments was 42.4 days (s.d. 24.1). The clinical diagnoses given to the 73 patients who participated in both measurements is presented in table 1. Descriptive statistics of the scores obtained in the first and second measurement are presented in table 2 .

Conversion symptoms and hostility. All correlations between the score changes of conversion symptoms and the HDHQ subscales were not statistically significant. All were positive, except that with Criticism of Others which was negative (Table 3).

Dissociative symptoms and hostility. Significant positive correlations were found with Total Hostility, Total Extrapunitiveness, and the extrapunitive subscales Acting Out Hostility, Paranoid Hostility, and Criticism of Others. Correlations with Self-Criticism and Total Intropunitiveness were negative and that of Guilt positive (all non significant) (Table 3).

\section{DISCUSSION}

It may be of importance to note that the relationships which were examined in this study were those between score changes after a lapse of time. This is a different approach to that used in other studies, where the relationships between hostility and psychiatric symptoms were examined on single occasions.

The main findings of the present study were the significant positive correlations between changes in dissociative symptoms and the extrapunitive forms of hostility. In general terms it would be said that as the dissociative symptoms became less marked so the patients expressed less extrapunitive forms of hostility. Changes in dissociative symptoms correlate significantly with changes in total hostility and with all the extrapunitive subscales.Conversion symptoms, on the other hand, do not correlate significantly with changes in these scales.It is also of interest that no significant correlations have been shown between the score changes of the in- 
tropunitive subscales with either conversion or dissociative symptoms.

In general the patients at the time of the study were recovering from acute mental illnesses, or relapses of them. Thus changes in symptomatology were mainly for the better. Similarly, although changes in hostility levels tend to follow a longer time course (Schmit and Priest, 1981) the tendency would be for the majority of patients to become less hostile over the period studied.

It is probable that both conversion and dissociative symptoms are at any point in time in fact related to extrapunitive tendencies but it seems that during the course of the alteration in symptomatology the changes in extrapunitiveness are more closely related to changes in dissociative symptoms. These findings are partially in accordance with the views expressed by some authors (Foulds, 1976; Eysenck, 1962; Caine and Hope, 1964) about the extraversion or extrapunitiveness of patients expressing hysterical symptomatology. Rosenweig's (1938) thesis on the intropunitiveness of the hysteric patients and Salmon's (1964) finding of no correlation between hysteria and extrapunitiveness may reflect the fact that their hysteric patients were manifesting conversion symptomatology. Fernardo's finding (1977) that hysterical manifestations correlate positively with guilt is not in accordance with the results of the present study and may reflect more specific relationships of these variables found in depressed patients.

Cameron (1963) stated that the disturbed physical function, which is the basis of conversion hysteria, is at the same time the expression of forbidden impulses, the defense against them and the self-punishment for having such impulses. This view gives an interpretation of the lack of association between conversion symptoms and the hostility subscales: a patient feeling that he is already punished through his symptom may not feel the urge to punish himself additionally, and since -again through his symptoms- he fulfils his psychological needs, mainly avoidance of the stressful situation, he may not feel frustrated by distressing demands of every day life, so the urge to be extrapunitive is not strong enough to need to be expressed.

However, for the patients reporting dissociative symptoms there must be a different explanation because their symptoms are closely related to extrapunitive scores. Why should changes in dissociation symptoms be correlated, within this overall picture, with changes in extroverted hostility? This difference could be attributed to the more "psychological" character of the dissociative symptoms. A possible explanation of the parallel movements of extrapunitiveness and dissociative symptoms may be that the formation of these symptoms could be regarded as an alternative outlet for intropunitiveness in a deeper - more psychotic-like level.If we are correct in inferring that dissociation symptoms are an alternative and disguised form of outlet for extrapunitiveness, then it may be that the as illness improves, those patients who feel less impulsive, critical or suspicious will also lose their need for dissociative symptoms. If this is the case, then we need to postulate an emotion other than anxiety in the mechanism of primary gain.

In describing the pathogenesis of hysterical symptoms, the diagnostic feature is that the patient achieves a primary gain from the development of the symptom. It is normally assumed that the primary gain is the loss of anxiety, or at least the lowering of anxiety levels. If our postulate is correct, then we must consider the possibility that the development of dissociative symptoms is also a mechanism for reducing distressing extrapunitive emotions. According to this viewpoint, as the patient experiences less in the way of uncomfortable feelings of criticism of others, suspicion and so on, so there is less need for protective dissociative symptoms such as lapses of memory.

\section{CONCLUSIONS}

In patients recovering from mental illnesses (acute or relapses), as the dissociative symptoms became less marked so the patients expressed less extrapunitive forms of hostility. Changes in dissociative symptoms correlate significantly with changes in total hostility, as well. Conversion symptoms, on the other hand, do not correlate significantly with changes in these scales. It is also of interest that no significant correlations have been shown between the score changes of the intropunitive subscales with either conversion or dissociative symptoms.

\section{ACKNOWLEDGEMENTS}

We wish to express our gratitude to Professor Priest, P.G. and to Dr. Raptopoulos, P. for their support in collecting and processing the data of this work. 


\section{REFERENCES}

[1] Akagi H, House A. (2002) The clinical epidemiology of hysteria: vanishingly rare, or just vanishing? Psychol Med; 32: 191-4

[2] Allam C, Toumi O, Benhassine N, Chena Fw, Bouyaghoub N, Bachiri M, Ahras A (2016)Conversion paralyses and physical medicine and rehabilitation: Four cases report. Ann Phys Rehabil Med. Sep;59S:e112-e113

[3] American Psychiatric Association (APA) Diagnostic and Statistical Manual of Mental Disorders: DSM-5. 5th ed. Washington, DC: Author; 2013.

[4] Armour C, Karstoft Ki, Richardson Jd(2014a)The co-occurrence of PTSD and dissociation: differentiating severe PTSD from dissociative-PTSD. Soc Psychiatry PsychiatrEpidemiol. Aug;49(8):1297-306.

[5] Armour C, Elklit A, Lauterbach D, ElhaiJd(2014b) The DSM-5 dissociative-PTSD subtype: can levels of depression, anxiety, hostility, and sleeping difficulties differentiate between dissociative-PTSD and PTSD in rape and sexual assault victims? J Anxiety Disord. May;28(4):418-26.

[6] Bedford, A., Foulds, G.A. (1978). Delusions Symptoms States Inventory State of Anxiety and Depression (Manual). NFER Publishing Co. Windsor.

[7] Blevins Ca, Weathers Fw, Witte Tk(2014)Dissociation and posttraumatic stress disorder: a latent profile analysis. J Trauma Stress. Aug;27(4):388-96.

[8] Brown RJ. (2005) Dissociation and conversion in psychogenic illness. In: Hallet M, Cloninger CR, Fahn S. ed. Psychogenic movement disorders: psychobiology and treatment of a functional disorder. Philadelphia: Lippincott Williams \&Wilkins;. p. 131-143.

[9] Brown RJ (2006)Different types of "dissociation" have different psychological mechanisms. J Trauma Dissociation;7(4):7-28.

[10] Caine Tm, Foulds Ga, Hope K. (1967). Manual of the Hostility and Direction of Hostility Questionnaire. London, University of London Press.

[11] Caine Tm, Hope K.(1964). Validation of the Maudsley Personality Inventory E scale. Brit. J. Psychol. 5(4):447-452.

[12] Cameron, N. (1963). Personality Development And Psychopathology. Houghton-Miffin. Boston.

[13] Christodoulou C, Efstathiou V, Ferentinos P, Poulios A, Papadopoulou A, Douzenis A (2016). Comparative study of hostility in depressive patients with and without a suicide attempt history. Psychol Health Med. Sep 22:1-6.

[14] ElbogenEb, Johnson SC (2009) The intricate link between violence and mental disorder: results from the National Epidemiologic Survey on Alcohol and Related Conditions. Arch Gen Psychiatry. Feb;66(2):152-61.

[15] Evren C, Cinar O, Evren B, Ulku M, Karabulut V (2013). The mediator roles of trait anxiety, hostility, and impulsivity in the association between childhood trauma and dissociation in male substance-dependent inpatients. Compr Psychiatry. Feb;54(2):158-66

[16] Eysenck, H.J. (1962). Response set, Authoritarianism and Personality Questionnaire. Brit. J. Soc. Clin. Psychol., 1:20-24.

[17] Fernardo, S.J.M. (1977). Hostility, Personality and Depression. Brit. J. Med. Psychol. 50, 243-249.

[18] Fleming Cj, Resick Pa (2016) Predicting three types of dissociation in female survivors of intimate partner violence. J Trauma Dissociation. May-Jun;17(3):267-85.

[19] FouldsGA. (1965). Personality and Personal Illness. Tavistock. London.

[20] FouldsGA.(1966). "Psychic: Somatic" symptoms and hostility. Brit. J. Soc. Clin. Psychol., 5:20-24.

[21] Foulds, G.A. (1976). The Hierarchical Nature of Personal Illness. London. Academic Press.

[22] Foulds, G.A., Hope, K. (1968). Manual of the Symptom Sign Inventory (SSI). London. University of London Press.
[23] Holmes Ea, Brown Rj, Mansell W, FearonRp, Hunter Ec, Frasquilho F, Oakley Da (2005)Are there two qualitatively distinct forms of dissociation? A review and some clinical implications. ClinPsychol Rev. Jan;25(1):1-23.

[24] Howard R (2015)Personality disorders and violence: what is the link? Borderline Personal DisordEmotDysregul. Sep 17;2:12.

[25] Humpston Cs, Walsh E, Oakley Da, Mehta Ma, Bell V, DeeleyQ (2016) The relationship between different types of dissociation and psychosis-like experiences in a non-clinical sample. Conscious Cogn. Apr;41:83-92.

[26] Ingham, J.G., Robinson, J.O. (1964). Personality in the diagnosis of hysteria. Brit. J. Psychol., 55:276-284.

[27] Jensen Bt, Hansen Cr (2016)Poster 173 Concussions Presenting with Conversion Disorder: A Case Series. PM R. Sep;8(9S):S218.

[28] Kendall, M.G. (1962). Rank Correlation Methods. Griffin, London.

[29] Lazare, A., Klerman, E.L. (1968). Hysteria and depression: The frequency and significance of hysterical personality features in hospitalized depressed women. Am. J. Psychiat. 124:48-56.

[30] Lerner, Harriet (1974). The hysterical personality: A "woman's disease". Compr. Psychiat.15(2):174-184.

[31] Mason CL (2016)When a patient falls (asleep) and can't get up: conversion disorder - Paraplegia following general anesthesia]. Rev Bras Anestesiol. 2016 Sep 19. pii: S0034-7094(16)30119-2.

[32] Norusis, M. (1992). SPSS for Windows: Base System Users Guide, Release 5.0 SPSS Inc. Chicago, Ill.

[33] Priest, R.G. (1971). The Edinburgh homeless: a psychiatric study. Amer. J. Psychother. 25(2):194-213.

[34] Rosenzweig, S. (1938). A general outline of frustration. Char. and Pers. 7:151-160.

[35] Ross E, Priest, R.G. (1970). The effect of hydroxysine on phenothiazine therapy: a method of study. Diseases of the Nervous System. 31:412-414.

[36] Salmon, Philida (1964). Fould'spunitiveness scales in relation to MMPI validation and diagnostic scales. Brit. J. Soc. Clin. Psychol., 4:207-213.

[37] Schmidt, R., Priest, R.G. (1981). The effects of termination of pregnancy: a follow-up study of psychiatric referrals. Brit. J. Med. Psychol. 54:267-276.

[38] Siegel, S. (1956). Non-Parametric Statistics for the Behavioural Sciences. Mc Graw Hill, New York.

[39] Watson, G.C., Buramen, Cheryl (1979). The frequencies of conversion reaction symptoms. J. Abnorm. Psychol. 88:209-211.

[40] Wolf Ej, Lunney Ca, Miller Mw, Resick Pa, Friedman Mj, SchnurrPP (2012) The dissociative subtype of PTSD: a replication and extension. Depress Anxiety. Aug;29(8):679-88.

[41] Woodruff, R.A., Goodwin, D.W., Guze, S.B. (1974). Psychiatric diagnosis. New York: Oxford University Press. 
Table1. Diagnoses given to the participating patients

\begin{tabular}{|l|c|c|}
\hline Clinical Diagnoses & Males $(\mathrm{N}=32)$ & Females $(\mathrm{N}=41)$ \\
\hline Neurotic Depression & 7 & 22 \\
\hline Schizophrenia & 18 & 6 \\
\hline Schizoaffective Disorder & 1 & 4 \\
\hline Personality Disorder & 2 & 3 \\
\hline Bipolar Illness (Depression) & - & 2 \\
\hline Bipolar Illness (Manic) & 1 & 1 \\
\hline Psychotic Depression & 2 & - \\
\hline Anxiety state & - & 2 \\
\hline
\end{tabular}

Table 2. Descriptive statistics of the scores obtained in the first and second measurement.

\begin{tabular}{|l|c|c|cc|}
\hline & $\begin{array}{c}\text { First } \\
\text { Measurement }\end{array}$ & $\begin{array}{c}\text { Second } \\
\text { Measurement }\end{array}$ & & \\
& mean (sd) & mean (sd) & \multicolumn{2}{|c|}{ Kendall's $\tau$-b } \\
& & & P & \\
\hline Conversion symptoms & $2.67(3.50)$ & $1.79(2.29)$ & .519 & .000 \\
\hline Dissociative symptoms & $1.96(2.52)$ & $1.42(2.19)$ & .592 & .000 \\
\hline Acting Out Hostility & $5.31(2.45)$ & $5.44(2.66)$ & & \\
\hline Criticism of Others & $5.18(2.45)$ & $4.92(2.84)$ & & \\
\hline Paranoid Hostility & $2.44(2.42)$ & $2.05(2.15)$ & & \\
\hline Self Criticism & $7.01(2.52)$ & $6.89(2.63)$ & & \\
\hline Guilt & $3.75(1.95)$ & $3.36(1.97)$ & & \\
\hline Extrapunitiveness & $12.93(5.29)$ & $12.41(5.85)$ & & \\
\hline Intropunitiveness & $10.76(5.29)$ & $10.25(4.03)$ & & \\
\hline Total Hostility & $23.70(7.33)$ & $22.66(8.23)$ & & \\
\hline
\end{tabular}


International Journal of New Technology and Research (IJNTR) ISSN:2454-4116, Volume-3, Issue-11, November 2017 Pages 18-24

Table 3. Correlations between the score changes of conversion symptoms, dissociative symptoms and the HDHQ subscales.

\begin{tabular}{|l|c|c|c|c|}
\hline & \multicolumn{2}{|c|}{$\begin{array}{c}\text { Conversion } \\
\text { symptoms }\end{array}$} & \multicolumn{2}{c|}{$\begin{array}{c}\text { Dissociative } \\
\text { symptoms }\end{array}$} \\
\hline & $\begin{array}{c}\text { Kendall's } \\
\tau-\mathrm{b}\end{array}$ & $\mathrm{p}$ & $\begin{array}{c}\text { Kendall's } \tau- \\
\mathrm{b}\end{array}$ & $\mathrm{p}$ \\
\hline Acting Out Hostility & .064 & .213 & $\mathbf{. 2 5 8}$ & $\mathbf{. 0 0 1}$ \\
\hline Criticism of Others & -.090 & .130 & .140 & .040 \\
\hline Paranoid Hostility & .032 & .343 &. $\mathbf{4 0 7}$ & $\mathbf{. 0 0 1}$ \\
\hline Self Criticism & .033 & .339 & -.104 & .097 \\
\hline Guilt & .042 & .300 & .054 & .250 \\
\hline Extrapunitiveness & .053 & .254 & $\mathbf{. 3 3 0}$ & $\mathbf{. 0 0 1}$ \\
\hline Intropunitiveness & .057 & .237 & -.058 & .236 \\
\hline Total Hostility & .034 & .309 & $\mathbf{. 2 5 6}$ & $\mathbf{. 0 0 1}$ \\
\hline
\end{tabular}

